\title{
Reflexiones sobre el transnacionalismo familiar en territorios de frontera
}

\author{
Menara Lube Guizardi \\ Pesquisadora pós-doutoral do Consejo Nacional de Investigaciones \\ Científicas y Tecnicas de Argentina (CONICET), Buenos Aires, Argentina; \\ pesquisadora associada da Universidad de Tarapacá, Arica, Chile \\ menaraguizardi@yahoo.com.br
}

Felipe Valdebenito Doutorando pela Universidad Católica del Norte, San Pedro de Atacama, Chile valdeb.felipe@gmail.com

Esteban Nazal Professor da Universidad Alberto Hurtado, Santiago, Chile enazalmoreno@gmail.com

Eleonora López Mestranda pela Universidad de Chile, Santiago, Chile eleonoralopezcontreras@gmail.com

Resumen Discutimos los resultados de una investigación etnográfica desarrollada entre 2012 y 2015 en la frontera chilenoperuana. En el estudio, realizamos 87 entrevistas cualitativas, 250 fotografias etnográficas, registramos toda la experiencia en 47 relatos semanales de trabajo de campo y aplicamos un survey a 100 migrantes peruanas. Analizando estos datos, reflexionamos sobre las definiciones de "familias migrantes transnacionales" buscando entender si esta categoría puede ser aplicada a territorios fronterizos. Partiremos sintetizando las discusiones sobre el transnacionalismo, las familias transnacionales y territorios fronterizos. Luego, señalamos la dialéctica constitución de la identidad nacional en la zona fronteriza; cuestionamos la relación conceptual entre vínculo y distancia planteada en la noción de familia transnacionalizada y criticamos la asunción del transnacionalismo familiar como un proceso de "desarrollo" de sujetos y comunidades. En las consideraciones finales, sintetizamos nuestras conclusiones conceptuales alrededor de tres ejes: replanteando el protagonismo de las mujeres 
como agentes de transnacionalización de las familias transfronterizas; cuestionando la dimensión espacial literal de las familias y proponiendo que la categorización de las familias migrantes en zonas de frontera expande el concepto de interseccionalidad de factores de exclusión de género.

Palabras clave: Familias transnacionales, migración, fronteras, género.

A veinticinco años del inicio de las teorizaciones sobre el transnacionalismo en los estudios migratorios, tanto el término como sus explicaciones más estructurantes están viviendo una (necesaria) revisión ${ }^{1}$. Este re-examen nos empuja hacia un cuestionamiento contextualizado de la perspectiva transnacional que la confronta con la heterogeneidad de los escenarios migratorios en diferentes parajes del globo. Nos conduce, además, a historizar la categoría, evitando darla por sentado o asumirla de modo sustantivado. El presente artículo endosa estas discusiones replanteando las definiciones sobre "las familias transnacionales" y buscando entender si esta categoría puede ser aplicada a territorios fronterizos.

Nuestras reflexiones teóricas nacen, no obstante, de una investigación antropológica desarrollada entre 2012 y 2015 sobre la experiencia de mujeres peruanas involucradas en actividades comerciales, agricultura, servicios domésticos o del cuidado entre Arica (Chile) y Tacna (Perú) ${ }^{2}$. Con alrededor de 190.000 habitantes, Arica se localiza en la costa del Pacífico y es la capital de la región chilena de Arica y Parinacota (Vicuña; Pérez; Rojas, 2015 , p. 38). Con una población superior a las 300.000 personas, Tacna es la capital del Departamento peruano homólogo y está a unos 52 kilómetros de Arica (Podestá, 2011, p.127). Estas áreas de la frontera chileno-peruana albergan espacios muy particulares, cuyo estudio demanda tener en mente la historicidad constitutiva de los territorios. La vida de los pueblos altiplánicos en el Atacama conllevó, históricamente, patrones de intensa movilidad humana y comercial (Almihat, 2007), pero esta interconexión fue violentamente atravesada por la conformación de las fronteras nacionales en el siglo XIX, especialmente desde la Guerra del Pacífico (1879-1883). El conflicto enfrentó a Chile a la Alianza entre Perú y Bolivia. Fue motivado a causa de las disputas por los territorios de explotación de salitre y guano en el desierto (Vitale, 2011, p. 387), situados en los departamentos de Tarapacá (antes peruano) y Antofagasta (boliviano). Chile "venció" el conflicto incorporando ambos departamentos a su geografia, pero las fronteras con Bolivia solo se establecieron en 1904 y con Perú en 1930. Esta victoria fundamentó la ideología de una diferencia racial entre chilenos, por un lado, y peruanos y bolivianos, por otro, asociándose los segundos a una identidad "india", "bárbara", "pagana" e “incivilizada" (McEvoy, 2011, p. 15). Institucionalizó, además, patrones de violencia de género vinculados a la militarización, patriarcado y masculinización imperantes en la

1 Ejemplo de ello fue el Workshop “Transnationalism at 25: Contributions, Limitations, and Future Prospects", realizado en el $50^{\circ}$ Congreso Internacional de la Latin American StudiesAssociation (LASA) de 2016, del que participaron autores fundantes del debate como Nina Glick Schiller, LuinGoldring y Robert Smith.

2 Agradecemos a la Comisión de Investigaciones Científicas y Tecnológicas de Chile (CONICYT) que financió el estudio a través del Proyecto FONDECYT 11121177. 
formación de las fronteras entre los países (Sater, 2007). Arica sirvió de puerto a Tacna desde el siglo XVI (Rosenblitt, 2013, p. 47) hasta la división de ambas entre Chile y Perú en 1930, tras 45 años de un violento litigio derivado de la Guerra (González, 2008, p. 14). Actualmente, estas ciudades catalizan rutas que entrecortan la Triple-frontera Andina (entre Chile, Perú y Bolivia) (Tapia; Parella, 2015, p. 196): se contabilizan 6 millones de cruces anuales entre el control fronterizo chileno de Chacalluta (en Arica) y el peruano de Santa Rosa (en Tacna) (Pérez et al., 2015, p. 52). Desde los años90, la migración peruana y boliviana a las regiones nortinas chilenas se magnificó debido a la demanda por mano de obra intensificada con la expansión e internacionalización de la industria minera en estos espacios. No obstante, esta migración tiene otros efectos, agudizando imaginarios chilenizadores de rechazo a peruanos y bolivianos (Tapia, 2012).

Interesados en entender la experiencia de las mujeres peruanas que migran a Arica, desarrollamos una investigación de enfoque mixto, cualitativo y cuantitativo. Realizamos etnografía en varios espacios por donde circulaban las mujeres peruanas: residencias, hospederías, campamentos, obras asistenciales de la iglesia católica, lugares laborales, de ocio, reparticiones públicas, puestos de salud y escuelas públicas. Realizamos 87 entrevistas, de las cuales 32 son historias de vida de mujeres peruanas. Las otras 55 constituyen entrevistas semi-estructuradas a hombres migrantes peruanos (10 en total); a mujeres bolivianas que compartían con las peruanas residencia en campamentos (6 en total); a líderes comunitarios de los barrios de concentración migrante (3 entrevistas); a personal de las ONG's y funcionarios de los centros de salud y educacionales que atienden a migrantes (21 entrevistas); y a mujeres peruanas en la Cárcel de Acha (15 entrevistas). Asimismo, registramos 250 fotografias etnográficas y recopilamos relatos de terreno para todo el periodo en campo.

Además, aplicamos una encuesta (survey) a 100 mujeres peruanas. Este contenía 106 preguntas divididas entre once ámbitos de indagación: 1) Información socio-demográfica; 2) Desplazamientos e itinerarios migrantes; 3) Educación y acceso a la educación formal; 4) Ocupación laboral; 4) Situación conyugal; 5) Situación residencial; 6) Situación documental; 7) Maternidad, hijos y familia; 8) Remesas a origen; 9) Relaciones de género; 10) Experiencias de violencia y 11) Razones para migrar. Tras la aplicación del instrumento, lo digitalizamos y analizamos contrastadamente los resultados.

Los datos arrojados nos permitieron, simultáneamente, "confrontarnos con" y "acercarnos a" la perspectiva transnacional de las migraciones. Por un lado, en la frontera tacno-ariqueña, encontramos formas de vida familiar que desafian los postulados "más clásicos" del transnacionalismo: experiencias que no tienen parangón con aquello que se describe en relación a las familias transnacionales emigradas al norte global. Precisamente, fue la experiencia de estos migrantes en las grandes ciudades estadounidenses o europeas lo que inspiró la construcción del concepto. Por lo general, se viene hablando de las comunidades y familias que circulan y viven en las zonas de frontera como "transfronterizas" y no "transnacionales", reconociendo con esta diferenciación que la vida fronteriza constituye los campos sociales entre países de una forma diferente a la que se observa con 
la articulación de las redes migrantes de larga distancia. Pero, por otro lado, esta división categórica tajante entre lo transnacional y lo transfronterizo nos resultó improductiva en términos explicativos, ya que también identificamos prácticas entre las familias peruanas que residen en Arica que coinciden con las descripciones más frecuentes de los estudios transnacionales. Así, el que las fronteras alberguen formas de vida migratoria particulares no implica que en ellas no existan redes y relaciones que podemos encontrar en otros espacios de recepción.

Para dar cuenta de estos debates, partiremos sintetizando en el segundo apartadolas discusiones sobre el transnacionalismo, las familias transnacionales y territorios fronterizos. En el tercero apartado, señalamos la dialéctica constitución de la identidad nacional en la zona fronteriza. En el cuarto, cuestionamos la relación conceptual entre vínculo y distancia planteada en la noción de familia transnacionalizada. En el quinto, criticamos la asunción del transnacionalismo familiar como un proceso de "desarrollo" de sujetos y comunidades, abordando la condición femenina fronteriza como parte de los procesos de subalternización que mantienen las mujeres en una posición contradictoria entre libertad y restricción. En las consideraciones finales, sintetizamos nuestro debate conceptual.

\section{Debates teóricos}

\section{El transnacionalismo}

La definición del transnacionalismo y de las metodologías para trabajarlo están lejos de constituir un consenso académico (Besserer, 2004, p. 6; Bryceson;Vuorela, 2002, p. 11; Moctezuma, 2008, p. 30). Según Glick-Schiller, Basch y Blanc-Szanton (1992) - autoras a quienes podríamos atribuir haber reinventado el término, traspasándolo de la economía a los estudios migratorios (Gonzálvez, 2007, p. 11) - los migrantes pasaron a experimentar, desde fines del siglo XX, contextos de globalización caracterizados por una revolución tecnológica de transportes y comunicaciones que abarató el coste de los viajes y posibilitó establecer contacto a tiempo real entre localidades distantes. Estos cambios permitieron que sujetos y colectividades constituyeran sus experiencias migratorias según patrones innovadores, repletos de vinculaciones imprevisibles: estableciendo relaciones (familiares, económicas, sociales, organizacionales, religiosas) de manera binacional o multinacional; tomando decisiones y prevenciones, constituyendo su acción y afectos, así como viviendo intereses que provocan una experiencia de conexión entre localidades distantes dentro de la simultaneidad temporal (Levitt; Glick-Schiller, 2004). Con ello, los migrantes articulan los denominados campos sociales transnacionales.

Esta última definición remite a Bourdieu (2011), y asume que los campos transnacionales están atravesados por diferentes formas de capital - social, cultural, simbólico, económico - que los sujetos van apropiando de acuerdo con las posibilidades y limitaciones que su posición en este campo (en relación a sus jerarquías y estructuras de distinción) condicionan. Así, el "transnacionalismo" propone que los migrantes están 
operando la renegociación de su asignación en relación a su posición y disposición dentro de las estructuras de los campos sociales de dos o más localidades (en dos o más países) simultáneamente. Se trataría, así, de cruces de los límites internos y externos del grupo de origen, pero condicionado por "procesos de participación en ambas regiones o localidades (emisoras y receptoras)" que "no se dan de manera independiente ni sucesiva, sino de manera dependiente y simultánea” (Baeza, 2012, p. 48).

Diversos autores (Massey et. al, 1993) preconizaron trabajar este campo migratorio transnacional enfocándose específicamente en cómo los migrantes articulan en él dos tipos de capitales: los sociales (usualmente identificados como las redes migratorias) y los culturales ${ }^{3}$. Otros, como Besserer (2004), al pensar en esta vinculación entre conocimientos y redes migrantes, hacen eco a la necesidad de entender las trayectorias subjetivas y comunidades transnacionales desde perspectivas menos materialistas del espacio (Besserer, 2004, p. 8).

Por lo general, se asume que el transnacionalismo actúa como el motor de una globalización “desde abajo” (Portes; Guarnizo; Landolt, 1999; Portes, 2003; Castles, 1997), que resulta de la agencia económica, política y sociocultural de grupos o sujetos que, cotidianamente, y quizás sin pretenderlo, subvierten ciertos designios del proyecto nacional que pregona el establecimiento de límites rígidos entre territorios.Así, al mismo tiempo en que aboga por el reconocimiento de esta forma de agencia migratoria, el transnacionalismo sedimenta la noción de que los procesos económicos globales y la continua persistencia de los Estados-nación como inscriptores de pertenencias siguen conectándose con las relaciones sociales, acciones políticas, lealtades, creencias e identidades de los migrantes en su vida cotidiana (Glick-Schiller; Basch; Blanc-Szanton, 1992). Pero siempre enfatizando la dimensión política de las restricciones que, más allá de toda circulación migratoria posible, no dejan de existir (Kearney, 1995, p. 548).

Uno de los ejes articuladores de la perspectiva transnacional de las migraciones es el que preconiza la re-conceptualización del papel de las familias en las movilidades humanas, reconociendo que la globalización provocó alteraciones fundamentales en la experiencia del tiempo y del espacio, y en el papel desempeñado por las mujeres en el marco de las redes parentales migrantes (Parreñas, 2005, p. 317). El argumento sobre las familias transnacionales asume, así, que las redes parentales y los hogares transnacionales operan como elementos centrales del proceso de globalización y de migración, constituyéndose como pilares analíticos y no como realidades accesorias (Parella, 2007, p. 159).

Hasta los años 80, las ciencias sociales reprodujeron la idea de que la familia podría delimitarse tal como se diseñaba las fronteras de un país: demarcándose en un espacio social dado las relaciones cotidianas entre todos sus miembros, la identidad familiar, las actividades económicas y los vínculos afectivos. Proyectada así, la familia era tomada como una metáfora de la nación. Una asunción centralmente problemática que naturalizaba el

3 El capital social migrante sería:"el conjunto de los recursos reales o potenciales que están vinculados a la posesión de una red duradera de relación más o menos institucionalizada de mutuo conocimiento o reconocimiento" (Bourdieu apud Portes, 2000, p. 45). El capital cultural correspondería a los conocimientos y recursos incorporados por los migrantes y difundidos a través de sus redes. 
concepto e invisibilizaba que familias y naciones - más allá de cualquier construcción sobre el lazo biológico - son comunidades imaginadas (Bryceson;Vuorela, 2002, p. 10) y elegidas (Gonzálvez; Acosta, 2015, p. 130).

Preconizando la necesidad de romper con las definiciones biologizantes de familia (Gonzávez;Acosta,2015,p. 131) - y también con aquellas que circunscriben la experiencia familiar a la contingencia de un espacio material compartido -, los debates sobre las familias transnacionales enfatizan el carácter espacialmente descentrado de las redes parentales:

Las 'familias transnacionales' se definen aquí como aquellas que viven una parte o la mayor parte del tiempo separadas unas de otras, pero se mantienen unidas y crean algo que puede ser visto como un sentimiento de bienestar y unidad colectivos, es decir, 'familiaridad' incluso a través de las fronteras nacionales (Bryceson;Vuorela, 2002, p. 3).

Así, para relativizar la importancia normativa de la noción de cercanía física y de relaciones como elemento central de la experiencia familiar, las autoras desplazan el concepto excesivamente (según lo entendemos) hacia el extremo opuesto de esta idea: asumen la distancia espacial literal como elemento definidor de la familia transnacional (Coe, 2011,p. 148; Parella,2007,p. 56; Sørensen;Vammen, 2014, p. 92). Este desplazamiento se opera sobre una episteme problemática: si bien le da la vuelta al argumento sobre la importancia de la cercanía física, nos ofrece también una definición de la familia transnacional sostenida sobre un principio espacial en el que, no obstante, el espacio está insuficientemente reflexionado (y, por ende, excesivamente literalizado, reificándose la idea de la existencia de una distancia geográfica medible entre miembros de la familia).

Pero esta asunción de la distancia literal como definición última del transnacionalismo familiar no constituye un consenso monolítico.Algunas autoras establecerán una definición alternativa que enfatizará como centro epistémico del concepto el tipo de relaciones y procesos de reproducción social de las familias transnacionales, y no necesariamente la distancia que separa a los integrantes del núcleo familiar:

Lo importante en este sentido es tener claro que cuando nos interesamos por las familias transnacionales nos interesamos por los grupos domésticos u hogares transnacionales (con actividades de producción y reproducción) dentro de un sistema de parentesco (personas vinculadas por lazos de primer grado tanto de afinidad u 'horizontales', díada conyugal o pareja, relaciones entre hermanos, como de consanguinidad o 'verticales', de ascendencia o descendencia), es decir, dentro de un sistema de relaciones, pero con la particularidad de que éstas se establecen más allá de las fronteras de un Estadonación. [...]. Es por ello que podríamos decir que cuando hablamos de hogares transnacionales hacemos referencia a las prácticas transnacionales y cuando hablamos de familias transnacionales nos referimos a las relaciones transnacionales (donde incluimos las prácticas), es decir, a los lazos familiares transnacionales que vienen determinados por el vivir transnacional. (Gonzálvez, 2007, p. 13). 
Por lo general, se critica en el concepto de familias transnacionales una reincidente tendencia a reproducir visiones sincrónicas de la vida familiar (Coe, 2011, p. 149) y esto es fundamentalmente importante en relación al estudio de las zonas de frontera, como trataremos a continuación. Otro importante eje de caracterización del concepto se refiere a la asunción, tomada con algo de generalidad entre los años 1990, de que la familia transnacional operaría como vehículo de procesos de "desarrollo humano" (Sørensen; Vammen, 2014, p. 93). Entre investigadoras feministas, hubo cierta euforia referida a la posibilidad de que el desplazamiento transnacional de las madres pudiera facilitar el empoderamiento económico femenino y la ruptura de las desigualdades de género -en las relaciones familiares y en el mercado productivo. Avanzada la primera década del siglo XXI, estas utopías fueron deconstruidas por la constatación que la maternidad transnacional exponencializa la sobrecarga de las mujeres migrantes en términos productivos, reproductivos y emocionales (Aranda, 2003; Hondagneu, 2000).

Es cierto que la amplia tradición de los estudios sobre género, cadenas globales del cuidado y migraciones transnacionales multiplicó las interpretaciones sobre la densidad, forma y definición de los vínculos de aquellas familias que se encuentran distendidas entre varios países debido a la migración de sus miembros. Pero, como dijimos anteriormente, persiste una especie de consideración (tanto de parte de los adeptos de los estudios transnacionales, como de los estudiosos de las fronteras) referida a que las familias migrantes, habitantes de territorios fronterizos, constituyen una realidad que excede a las pretensiones conceptuales del transnacionalismo. Aunque muchos autores hayan intentado acercar estos debates, aún opera un sentido común académico según el cual las familias que viven en regiones de frontera son "transfronterizas" y no "transnacionales".

\section{Fronteras}

En los primeros trabajos dedicados al debate sobre las comunidades migrantes transnacionales, las fronteras se convierten, contradictoriamente, en un elemento crucial e invisibilizado. Crucial porque el acto de atravesarlas se asume como el estopín del proceso que dota al sujeto migrante de transnacionalidad. Invisibilizado porque gran parte de los estudios iniciales priorizó trabajar las comunidades migrantes en grandes centros urbanos del norte global que están lejanos a las fronteras, careciendo de una problematización sobre las áreas en tanto productoras de experiencias de movilidad humana que (re)configuran lo nacional. Muchos investigadores pasaron a usar la noción de "cruce fronterizo" predominantemente de forma metafórica, aludiendo al tipo de desplazamiento social, cultural, político e identitario que los migrantes viven en las localidades de destino.

La problematización sobre el papel de las zonas fronterizas como espacios de estudio vendría de la mano de investigadores que, trabajando en estos territorios, empiezan a generar categorías particulares para pensar el tipo de interconexión entre Estadosnaciones y localidades que nacen, precisamente, de los desplazamientos en estas áreas. Se pasa a discutir estos territorios como condensadores de fenómenos multiescalares (Sum, 2003) que desafian las ideologías fundantes del Estado-nacional (Kearney, 1991), 
dinamizando formas de vida estructuradas alrededor de la movilidad. Esto lleva a los investigadores a distender el propio concepto de "migraciones", para abarcar procesos de bi-residencialidad transfronterizos que se asemejan más a una lógica circular "entreespacios". Se asume, además, que la condición fronteriza altera las relaciones entre la acción de personas o grupos, y las características macro-estructurales del contexto, engendrándose la construcción de "lo local" a procesos de mutua conformación global (Kearney, 1995, 1991). Así, estas relaciones serían inherentemente "dialécticas y problemáticas" (Agnew, 2008, p. 175). Atentos a las "dialécticas en la frontera" (Wilson; Donnan, 1998, p. 3) - entre movilidad y restricción; legalidad e ilegalidad; pertenencia y desarraigo -, los antropólogos anglosajones pasaron a teorizar los espacios fronterizos a partir de la tensión entre sujeto, historia y cultura en los años 90 (Grimson, 2003, p. 15).

La antropología sudamericana siguió estas reflexiones. Grimson (2000, p. 28), por ejemplo, señaló que la porosidad de las fronteras, no implica necesariamente la "modificación de las clasificaciones identitarias y autofiliaciones nacionales. Más bien, es sobre la existencia de la frontera que se organiza un sistema social de intercambios entre grupos que se consideran distintos". El que la gente cruce fronteras no determina la desaparición de las mismas (Cardin, 2012). Las asimetrías jurídicas, políticas, económicas e identitarias entre las naciones colindantes, aceleradas por la globalización, provocarían la emergencia de prácticas sociales que buscan beneficiarse de estas diferencias a partir de liminalidad entre lícito e ilícito y entre pertenencia y desarraigo (Grimson, 2005). Estas prácticas usan la circularidad transfronteriza para lograr beneficios e intereses.

En los años 2000, la sociabilidad dialéctica articulada en las zonas fronterizas fue asumida por los investigadores como una excepcionalidad que justificaba que los grupos sociales y familias en estos territorios recibieran una denominación propia:"comunidades transfronterizas". A partir del año 2010, el término ganó nueva relevancia en los debates sobre las experiencias de movilidad post-globalizadas:

Dado que la mayoría de los procesos de migración e inmigración implican históricamente el cruce de las fronteras étnicas, raciales, culturales, coloniales, regionales y estatales, así como de las fronteras nacionales, el concepto de transfronterizo es más amplio que 'transnacional', que, como etiqueta que enfatiza lo nacional y el control de las fronteras por el Estado, termina centrando al Estado-nación como la principal entidad con la cual los migrantes interaccionan. (Stephen, 2012, p. 456).

Este argumento afirma que las comunidades fronterizas constituyen realidades condensadoras de las contradicciones, paradojas, diferencias y conflictos de poder entre el capitalismo contemporáneo global y los Estados-nación; y que sus prácticas locales configuran un entramado disruptivo de las asimetrías globales (Álvarez Jr., 1995, p. 447). Stephen (2012, p. 473) enumera algunos puntos definitorios de estas particularidades de las comunidades transfronterizas a los que enuncia como oposición a la definición de comunidades transnacionales. 
Primeramente, se tratan de comunidades con trayectorias históricas y actuales muy complejas, lo que demanda el uso interconectado de diversas herramientas analíticas. En segundo lugar, en los estudios transnacionales, se enfatiza la acción de individuos conectados entre sí a través de la migración hacia espacios lejanos y reproduciendo formas de "nacionalismo de larga distancia" (Stephen, 2012, p. 473). En las zonas transfronterizas, sin embargo, formas muy diferentes de construir la conexión entre sujetos y comunidades tienen lugar y, desde allí, habría que abandonar visiones etnocéntricas que sobre-enfatizan al individuo, para dar más énfasis a las redes familiares, sociales, políticas.

Un tercer punto afirma que la transfrontericidad provoca una experiencia de simultaneidad entre espacios nacionales mucho más radical que la migración transnacional de larga distancia; provocando, por ende, una interacción más intensa entre elementos constitutivos de la interseccionalidad de los sujetos en el campo social. La historicidad - de lo nacional, de lo regional y de lo local - son tanto más complejas entre las comunidades fronterizas y requieren una visión muy refinada sobre las heterogeneidades constitutivas de los grupos sociales en el espacio local. Stephen hace hincapié en que la visión sincrónica, que el argumento transnacional muy a menudo reproduce, no puede ser aplicada en las comunidades fronterizas.

Finalmente, Stephen (2012, p. 473) propone que el estudio de comunidades transfronterizas - como las familias, por ejemplo - debe ser construido a partir del análisis sobre los diversos cruces de frontera (literales y metafóricas) que sus miembros realizan y experimentan. El análisis de cómo los sujetos logran realizar estos cruces nos permitiría, dice, comprender el tipo de agencia que las personas pueden personificar frente al Estado-nación. Las familias, en cuanto comunidades transfronterizas, estarían caracterizadas por la interseccionalidad de formas diversas de frontera que, no obstante, son desafiadas situacionalmente - de acuerdo a las posibilidades históricas del contexto -, por sus integrantes (Márquez; Romo, 2008, p. 1).

\section{Hacia una ontología histórica de las familias transnacionales en la frontera}

Entre los varios "cables sueltos" de la perspectiva transnacional, nos interesa especialmente la noción referida a que ciertas comunidades y familias migrantes se transnacionalizaron progresivamente en la medida que la globalización generalizó el acceso a ciertos circuitos productivos, barateando medios de comunicación y transporte. Hay en este argumento una lógica ontologizante según la cual las posibilidades estructurales de la globalización son un requisito y una causa de la transnacionalidad progresiva de las comunidades migratorias (incluso cuando esta condición transnacional esté fuertemente condicionada por la agencia de los migrantes: por su acción y por su apropiación de las posibilidades contextuales).

En nuestra experiencia etnográfica entre Arica y Tacna, nos dimos cuenta que esta lógica ontologizante no siempre es aplicable y que la tendencia a asumirla apriorísticamente inclina los investigadores a asumir posturas teleológicas. Paralelamente, observamos que, 
cuando son enfrentadas a territorios fronterizos, las categorías y explicaciones de la perspectiva transnacional suponían, frecuentemente, retratos invertidos de aquellas escenas y procesos que buscábamos comprender. En la frontera, las categorías transnacionales padecían de múltiples problemas de escala.

En primer lugar porque la historia de la transnacionalización de aquellos territorios donde hacíamos etnografia no podría ser contada según la lógica: "primero vino la globalización; luego...". Al contrario, los espacios presentaban patrones históricos de interconexión que habían servido como base para la forma como la globalización se institucionalizaría allí. Y esto era central para comprender la estructura transnacional y transfronteriza de las familias, pero también las relaciones entre territorios, etnicidad, identidades nacionales y circuitos económicos.

Muchas de las familias peruanas que antes de la chilenización de Arica vivían en esta ciudad, se mantuvieron fieles a su nacionalidad peruana en el periodo de litigio de este territorio (entre 1883 y 1930). Algunos de los integrantes de estas familias migraron tras el establecimiento de la frontera en 1930, para evitar las persecuciones y violencias en el territorio anexado a Chile. Ellos pasaron a ser considerados extranjeros en su propio pueblo de origen entre el final de la guerra (en 1883) y el establecimiento formal de los límites nacionales (en 1930). Es decir, muchos de los peruanos que se resistieron a dejar Arica con la chilenización del territorio se convirtieron en población migrante sin migrar. Para otros, que aceptaron adherir a la ciudadanía chilena, la imposición de la chilenización fue el estopín de la transnacionalización de la red familiar, dividiendo personas que quedaron de un lado y otro de la frontera (algunas manteniendo su peruanidad y otras convirtiéndose a la chilenidad), pero manteniendo sus redes e intercambios. Así, la frontera transnacionaliza a las familias de forma heterogénea, y el transnacionalismo no es un producto del paso del siglo XX al XXI. Las familias fueron transnacionalizadas casi un siglo antes de la globalización. No estamos hablando, por ende, de las familias transnacionales como motores de una "globalización desde abajo", como preconiza Portes (2003). Esto es justamente lo que dicen los analistas Wilson y Donnan (1998, p. 10) cuando afirman que, en las fronteras, la relación entre las identidades y el poder del Estado es problemática debido a la liminalidad de la condición fronteriza según la cual los sujetos se imaginan para sí afiliaciones muy diferentes y mucho más maleables que aquellas que el Estado (desde sus espacios centrales de poder) desea otorgarles (Wilson; Donnan, 1998, p. 13).

Nos encontramos, así, con una primera contradicción dialéctica en la forma como los sujetos experimentan los sentidos y límites entre las identidades (trans)nacionales y familiares en la frontera.En una zona en la que la nacionalización a través de la militarización del espacio no ha cesado desde el siglo XIX, en que los Estados invierten un esfuerzo significativo en producir y mantener el sentido de diferenciación de las nacionalidades, pareciera que la mantención del sentido de afiliación a localidades, comunidades y familias ha venido a provocar en los sujetos formas selectivas de desdibujar la identificación de los propios antepasados que tuvieron sus identidades atravesadas por la frontera nacional. La reincidente clasificación y etiquetaje nacional de las personas en las experiencias 
sociales cotidianas que observamos en Arica es simultánea a un ejercicio opuesto: el de disolución de la memoria sobre las identidades nacionales pasadas. Por ello, la fijación de esta clasificación de nacionalidad de los antepasados parecía, a chilenos y peruanos, un ejercicio extrañísimo; que solo tenía sentido para unos investigadores (nosotros) que no terminaban de entender cómo las familias de la frontera, desde sus particulares claves de memoria, construyen sus identidades nacionales. Aquí, retomando a Coe (2011, p. 149), es necesario superar la tendencia a asumir sin la necesaria crítica que la experiencia de transnacionalización de las familias es un fenómeno "nuevo".

Estas consideraciones nos empujan a la necesidad de asumir la translocalidad ontológica de los capitales sociales y culturales que ahora se interpretan como "transnacionales" en las zonas fronterizas. Parte de las redes sociales y de los conocimientos sobre la vida en desplazamiento de las mujeres entrevistadas y de sus familias es anterior al establecimiento de los límites nacionales entre Tacna y Arica. Sus prácticas de movilidad constituyen experiencias de larga duración que remontan a sus abuelas(os) y bisabuelas(os).

Sobre lo anterior, subrayábamos la acción de los Estados que, al generar la frontera y cambiar las afiliaciones nacionales de la gente, construyeron identidades transnacionales entre familias que antes se consideraban "peruanas".Al emprender actividades comerciales, laborales, sociales y religiosas entre Tacna y Arica las mujeres están, en realidad, reproduciendo un capital social y cultural familiar:

Y después seguía trabajando... También vinieron mis hermanos a trabajar [en Arica], todos mis hermanos, hasta mi papá, mi mamá, todos vinieron, pero ellos se hicieron su platita y todos se fueron (VP, 38 años).

Bueno mi mamá, mi mamá tenía 18 años cuando se fue de su casa en Lima. Ella se fue de su casa y llegó a Tacna, andaba viendo y ahí luego, y ahí se conocieron [sus padres] [...]. A ver: lo que pasa es que la familia, la familia de mi papá... No... De mi abuelito; la familia de mi abuelito, el papá de mi papá, vive acá en Tacna. Entonces ellos se fueron trasladando a Ilo por el trabajo de mi abuelito, que también era en la Southern [industria minera cuprífera en Perú] y ahí lo contrataron a mi papá como chofer, también para la Southern. No de camiones, sino de personas. Mi papá trasladaba a los jefes: los llevaba a Tacna, a Ilo, a Lima, a Arequipa, a los jefes (Blanca, 29 años).

Mi mamá nació en un pueblo de, de, del Perú que se llama Asillo [...]. Es departamento de Sicuani, Provincia de Puno [...] Bueno la necesidad le dio de hacerse negocian... comerciante. Se tuvo que hacer de comercio, comercio ambulante. Ahí hay que ingeniársela, buscársela de todo, de todo. [...] Ella vendía como, porque hay muchas mujeres que venían a Tacna compraban mercancías se devolvían a Puno para vender (Meche, 31 años).

Casi en la totalidad de las entrevistas fue relatada una intensa experiencia migratoria familiar de padres y madres de las y los migrantes: tanto interna en el Perú, como también hacia Arica. Al mismo tiempo, esta movilidad hacia otras ciudades como Putre e Iquique, que fueron chilenizadas, son mencionadas como un pasado familiar muy presente en las 
historias de abuelos y abuelas (que se desplazaban antes de que estas localidades dejasen de ser peruanas). Una vez más, insistimos en que no fueron las migrantes, propiamente, quienes transnacionalizaron "desde abajo" el territorio. La frontera les ha transnacionalizado sus prácticas familiares.

\section{Repensar la relación entre familia transnacional y distancia}

En Arica, las mujeres peruanas están muy cerca del territorio nacional peruano y, por ello, algunas de ellas podían efectivamente ver a sus hijos(as), padres, madres y hermanos(as) semanalmente. La distancia física no es tan apremiante, pero la dimensión transnacional de sus familias no se disuelve por ello. En este sentido, nos parece que la aceptación de la distancia física como una característica central de las familias transnacionales (Coe, 2011, p. 148; Sørensen;Vammen, 2014, p. 92) debe ser replanteado.

Esto es tanto más relevante cuando observamos, en las narraciones de las mujeres peruanas, que, su condición transfronteriza - su supuesta cercanía a la localidad donde están sus familias -, no impide que sus hijos(as), madres, padres y demás familiares vivan su condición migratoria como una lejanía:

Mi hijito me dijo: 'mamita no te vayas'. Yo le dije: 'hijito voy a trabajar'; 'no mamita, ¿Quién me va a cocinar mi caldito?’ Así se puso a llorar mi hijito. 'No hijito, voy a ir a trabajar para comprarte muchas cositas'. Así le dije y ahí se calmó mi hijito. 'Yo te voy a traer yogurt' [...].Yo le dije que voy a regresar:'ya el domingo estoy ahí', le dije así [...]. El domingo sí, por la tarde. Mi hijita está más apegada al papá, pero mi hijito es el que sufre (Gladys, 34 años).

Entonces en eso ando. Pero, de repente, también, digo [que] hay gente que dirá: 'oye, mira esta mujer, dejó sus hijos, y ella está por otro lado'. [...] ¡No! Todo lo que tenía que hacer lo hice para que no les falte; para darles de comer, para que no pasen como yo pasé, hambre, estirando de repente [...]. Esta vida es así; de repente le llegan visitas y un viejo le sonríe: 'ya, ¿cuánto quieres? Te doy'. Eso no quiero para mis hijos, yo no quiero. Sería muy triste que mis hijos caigan en eso, tampoco son drogadictos. Entonces, de eso doy gracias a Dios (Guerrera, 54 años).

Yo le dije ayer mismo eso, cuando le agarré del pelo.Toda su ropa le he tirado al patio. Porque me molesta que yo le compre las cosas para que estén así.Y yo no tenía ni eso. Ahí yo le doy todo lo que puedo de mí, y entonces... Ella lo deja así, botado, lo arrincona. Está todo ahí: pudriéndose, mojándolo. A mí me cuestan. Ella tiene sus comodidades ¿O acaso ella pone su ropa nueva en un cajoncito, o en una bolsa? ¡No, po! Ella tiene su cómoda, tiene su tele, tiene todo ahí. No será lujoso, pero ella tiene lo que es lo justo y necesario... Ya pues, entonces ella no cuida tampoco eso... Ahora tenía problemas de desorden alimenticio, eso también otro problema era [...] ¿Cómo me dijo un día?: 'el perro me es más familiar que tú, porque tú no estás'. 'Bueno, entonces dile al perro que te dé de comer, pues' [risas]. 'Así, vívete del perro. Si no me conoces, no tienes idea de lo que hago'. Dije: 'te quiero mucho, 
hija, pero te voy a decir algo: te das cuenta de lo que estás haciendo. Conoces lo bueno y lo malo.Yo solo sé que de ti depende tu futuro' (Lolis, 39 años).

Los tres ejemplos demuestran casos de creciente complejidad en relación a la lejanía construida de las madres que migran a trabajar en el lado chileno de la frontera, dejando sus hijos e hijas en Perú. Gladys iba a Tacna una vez por semana y, aun así, su hijo sentía su distancia como una separación muy dolorosa. Guerrera sufría a distancia por la culpa de tener a sus hijas en Perú y por el peligro de que éstas se entregaran a la prostitución en su ausencia. Lolis escuchó de su hija que hasta "el perro" le era más familiar que su propia mamá.

Leyendo estos tres ejemplos - entre otros tantos recopilados -, ¿quién podría decir que el migrar a la frontera implica cercanía, debido a la supuestamente pequeña distancia entre las ciudades fronterizas? Nos puede parecer que estas madres y sus hijos están cerca, pero, para estos últimos, los 52 kilómetros que separan Tacna de Arica se sienten como una distancia insalvable, como un abandono. Por ello, las mujeres viven presiones - propias y ajenas - y angustias muy semejantes a las que viven las migrantes que ejercen una maternidad transnacional de larga distancia. Así las cosas, habría que asumir que la "distancia" entre los miembros de la familia transnacional es una realidad construida e imaginada. Mirándolo de esta forma, las madres cuyas narraciones reproducimos arriba están, efectivamente, viviendo una experiencia de maternidad transnacional.

Los datos de nuestra encuesta nos añaden otro elemento para complejizar este análisis. Solo un 19\% de las mujeres que entrevistamos dicen ser originarias de Tacna. El $81 \%$ restantes provienen de departamentos y provincias menos cercanos a la frontera, con los cuales la comunicación vial por carretera es bastante compleja, demorosa y onerosa (para los patrones de renta de las migrantes). El12\% de las encuestadas provenía de Puno y otros 12\%de Lima. El 67\% restante de las encuestadas son originarias de 39 distritos diferentes, todos ellos a distancias de más de 300 kilómetros de la frontera con Chile en espacios del sur peruano donde los caminos son precarios.

Estos datos nos fuerzan a admitir que la suposición de que las mujeres que migran a Arica están más cercanas (en términos de distancia espacial literal) de sus hijos(as) que quedan en el Perú no es correcta. Ella solo es correcta si uno considera que todas las mujeres tienen sus hijos en el Perú los han dejado en Tacna, asunción que no se ha confirmado ni en las entrevistas, ni en las encuestas. Así, habría que deconstruir la noción de que estar en la frontera implica realmente cercanía en términos de distancia espacial medible.

Por otro lado, la misma presión que ejercen los Estados-nación sobre la construcción de frontera y el "deber ser" de las familias generan distancias sociales que se reifican como distancias espaciales para los miembros distanciados de las redes parentales transnacionales y transfronterizas. Así, las mujeres que tuvieron hijos en el lado chileno, nos cuentan que ellos sufren discriminaciones en la escuela pública ariqueña, a la vez que son rechazados por primos y hermanos nacidos del lado peruano. 
Hay aún otro aspecto que añadir en este punto. El que muchas familias peruanas en Arica vivan circularmente entre Chile y Perú no implica necesariamente que esas mismas familias no estén compuestas por redes transnacionales más distendidas que el eje tacnoariqueño. Recordando la manera como "todo se inició", MF (hombre peruano que vive entre Arica y Tacna) nos explica que el liderazgo migratorio en la familia fue de su mujer, para quién la realidad transnacional configuraba un capital cultural femenino:

Le dijo que 'en Chile hay trabajo, buena pega', porque en Chile ella tenía una amiga que hace un año estaba allá. [...] Pero mi señora me decía, ‘¿No conoces Antofagasta?’ y yo le decía ‘que voy a conocer Antofagasta, si conozco hasta Puno no más'. 'Vamos', me decía ella.Yo le decía 'No'. Porque yo viajo a la montaña, todo lo que es serranía del Perú. [...] Dentro del Perú. Y yo le dije 've tú' pues. 'Sí, hay que hacer el intento', me dice. Ellas fueron las que vinieron primero con su amiga. Vinieron tres, dos son sus amigas más ella, son tres. Acá había una señora que la otra muchacha la trajo. [...] Estuvo sola como tres, cuatro meses y me comunicaba, siempre estábamos comunicándonos. [...] Yo me quedé con mis hijos. [...] Mi señora me habló y me ayudó cuando me vine con mi hija. (MF, 40 años).

MF estaba habituado a una vida en desplazamiento: migraba internamente en Perú para sortear las dificultades económicas del entorno, ejerciendo como albañil, comerciante y transportista de productos. Pero son las amigas de su esposa y ella misma las que validan el intento de cruzar las fronteras nacionales en dirección a otros itinerarios migratorios. Acá notamos una diferencia fundamental en el protagonismo de género respecto a las posibilidades del desplazamiento (hacia dónde migrar, con quién migrar, cuándo migrar). Es su mujer quien emprende el viaje, siendo además acompañada e incentivada por otras mujeres.

Hombres y mujeres peruanos que entrevistamos encuentran plausible la migración femenina como forma de evaluar inicialmente la posibilidad de encontrar trabajo en Arica. No están de acuerdo en relación a las posibilidades y limitaciones que esto pudiera implicar, pero aceptan que la mujer pueda desplazarse sola y que financie el viaje de su pareja, una vez activadas las estrategias necesarias para sobrevivir y trabajar en el nuevo contexto. Constatamos la existencia de una libertad de circulación femenina que es supeditada a la responsabilidad de concentrar y adquirir - como cabezas de redes migratorias - los capitales económicos suficientes para la adaptación del núcleo familiar al nuevo contexto. Al actuar como protagonistas de la red migrante y punto de apoyo a la migración de sus maridos, estas mujeres también hacen posible que la adquisición del capital cultural migratorio no solo se remita a la experiencia personal de los hombres. Cuando preguntamos por qué le parecía normal o aceptable que su mujer migrara sola y antes que él, MF reaccionó con sorpresa. Le parecía del todo lógico que lo hiciera, ya que ésta había sido la historia de muchas mujeres de la familia de su esposa:

Primero su mamá, ellos se fueron allá [a Estados Unidos de América], son nacionalizados allá, y viene mi suegra como a los doce años [tras doce años 
en Estados Unidos] va a venir para acá, para el Perú y se comunica conmigo con el Internet. [...] Los primeros [en migrar a Estados Unidos], su hermano se fue más mayor, fue el primero que se fue. Ese vive en el centro de los Estados Unidos, este, en el corazón de Estados Unidos, este, Nueva York. [...] Su hermana se fue por lo menos, la señora tiene trece, como veinte años será [viviendo fuera del Perú], su hermana que llegó primero. [...] Primero se fue su hermano, después los mando a llamar por Colombia sin escala. Así se fueron, y ahora son residentes en Estados Unidos (MF, 40 años).

La aceptación por parte de MF respecto al protagonismo migratorio de su mujer se condice análogamente con el hecho de que las mujeres de la familia de ella hayan consolidado una experiencia migrante que ha movido hombres y mujeres hacia países distantes, construyendo así una comprensión de la migración feminizada como legítima e integrada a las funciones que ellas cumplen como reproductoras sociales. En la práctica familiar se diseña un rol femenino que abre caminos, impulsando el desplazamiento masculino. La experiencia en Estados Unidos no estuvo al alcance de MF, pero su toma de conocimiento de aquel lugar como un espacio de posibilidad migratoria también es provechosa en tanto capital cultural, y en cuanto deja una marca transnacional en la forma como él y su mujer diseñan estrategias migratorias hacia la frontera chileno-peruana. El ejemplo llama la atención a que las familias que viven en la frontera están, en muchos casos, vinculadas a redes transnacionales de larga distancia con otros miembros del núcleo familiar.

\section{Deconstruir la transnacionalidad familiar como "desarrollo"}

Nos resulta problemática la idea de que la vida transnacional de las familias las puede conducir hacia el "desarrollo humano" (Sørensen; Vammen, 2014, p. 93). Además de nuestras profundas dudas sobre el contenido neo-colonialista de esta expresión, nos resulta poco factible pensar en la experiencia migratoria de las familias transnacionales como un juego de sumas positivas, donde todos salen ganando. Por lo menos en las vidas de las mujeres migrantes peruanas con las que trabajamos, su proceso de transnacionalización las sobrecarga con aun más obligaciones sociales en relación a la reproducción social de las familias y ellas asisten, frecuentemente, un empeoramiento de sus condiciones de salud, de habitabilidad y de ocio. Esto sin mencionar la sobrecarga emocional y la ambivalencia provocada por la sensación de culpa por “abandonar” la familia del otro lado de la frontera:

A veces $[\ldots]$ como un mes estaba sin trabajo.Y ahí yo me iba a la chacra, a las parcelas que están acá.Y ahí sí lloraba. Ahí sí decía: ‘Porqué tengo que estar acá? ¿Porqué pasa esto?’ Lloraba por el papá de mi hija pues, 'él está bien y yo estoy así' [...]. Así es [el trabajo en las chacras]. Es feo: te quemas, te quemas. Sol, feo, feo es la chacra (Mary, 34 años).

Y he tenido hartos problemas también para poder trabajar. Porque yo, a mí me gusta trabajar independiente. Porque he tenido problemas así, trabajar para los dueños porque me pagaban muy poco. Me pagaban al día. Me pagaban 
como cinco mil pesos [7dólares estadounidenses]. O no me dan almuerzo. El pasaje [para pago del transporte] aparte (GDR, edad desconocida).

Nunca tuve contrato. No, nunca, ellos decían que no lo podían hacer tampoco. Una, porque tenían que pagar de cesante... tenían que pagar tanto la persona y el...las imposiciones. Entonces ellos no querían pagar eso. Hasta ahora están así, no quieren pagar imposiciones (Rosa, 53 años).

Observamos, en el relato de Mary, que su precarización no encuentra paralelo en la precarización del padre de su hija, quién, habiendo permanecido en el lado peruano, trabajaba con contrato y derechos laborales.Vemos entonces cómo la mejora económica de las familias ocasionada por el incremento del recurso económico vía remesas está producida por el empeoramiento de las condiciones de vida de algunas de las mujeres que son protagonistas de la transnacionalización de la familia. Diversas autoras observaron que la experiencia de la maternidad transnacional empuja a las mujeres al agravamiento de su centralidad en la reproducción social de las familias (Gonzálvez, 2013; Gonzálvez; Acosta, 2015). Esto es exactamente lo que hemos encontrado en la frontera ${ }^{4}$. Pero allí, donde los trabajos son aún menos formalizados que en territorios más céntricos de los países, las mujeres están expuestas a patrones especialmente intensos de precarización y malos tratos laborales.

Asimismo, identificamos que las mujeres están brutalmente expuestas a experiencias de discriminación y xenofobia en Arica, las cuales generan en ellas un rechazo a traer a sus hijos a vivir con ellas (ante el riesgo de que ellos padezcan de estas mismas circunstancias):

No, si yo pasé tantas cosas... Los años que trabajé, pasé muchas cosas. Por eso no quiero que mis hijos vengan para acá.Yo quiero que estén tranquilos. Aunque se pueda ganar más plata acá...Mejor que estén allá. Acá, como le digo, hay mucha discriminación. Si po, todos somos humanos, no somos tampoco... por el hecho de que somos de otro lado, vaya a haber animales, pero así. [...] No, por la misma razón de que acá hay mucho racista... ¡No!Yo nomás: por esa razón no los traigo. Prefiero yo sufrir; no que ellos lo sufran (Rosa, 53 años).

A ella [su hija] no le gusta venir para acá. No, ella no quiere que venga para acá, no quiere, porque ella escucha... A veces ve en la tele, así, que hablan mal de los peruanos. Entonces ahí me dice: 'Mamá yo no quiero que vayas allá, quédate acá en Tacna, quédate en costuras o anda a trabajar'. Pero ella no

4 Nuestra encuesta arrojó que el 63\% de las migrantes envía ayuda económica a Perú. En relación a la frecuencia de estas remesas, el $41 \%$ de las que remiten dinero afirma que lo hace mensualmente; el 29\% todas las semanas; el 11\% envía entre dos o cinco veces por año; el 7\%, una vez al año; el 5\% a cada vez que van de visita (lo que puede ser todas las semanas, para algunas mujeres) y otro $5 \%$ dice que lo envían cuando se lo piden los familiares. Un $2 \%$ de las mujeres apuntan otros patrones más variados en temporalidad del envío. El principal uso primario dado en Perú a las remesas enviadas por las encuestadas es "la manutención de la familia" (62\%), seguido de "gastos educativos" (21\%), el "pago de deudas" o "gastos de salud" (con 5\% en ambos casos) y, "mejoras a la vivienda" y "ahorro" (con $2 \%$ en ambos casos). 
quiere que venga para acá. Siempre me dice: 'Cuídate, cuídate', me dice. O escucha también que han muerto, lo han matado, ha ido a la parcela y no ha regresado, entonces por eso ya no quiere. (Mary, 34 años).

Relatos de precariedad laboral, sobrecarga económica, dificultades afectivas, conflictos con las parejas y la reincidencia de experiencias de maltrato racista y discriminador en el lado chileno nos autorizan a decir que las familias no se están desarrollando en un sentido positivo para ellas mismas: sino que se agravan los patrones interseccionales de exclusión de las mujeres, en favor del incremento del recurso económico familiar. En esto, las mujeres fronterizas viven circunstancias muy semejantes a las que la literatura de los estudios migratorios ha descripto en relación a las mujeres jefas de familias transnacionales de larga distancia.Y esta semejanza no debiera ser borrada, dado que enuncia la particularidad del abuso hacia las mujeres como un patrón globalizado, remitiendo a la construcción global de circuitos de la explotación de género.

\section{Consideraciones Finales}

Nos gustaría finalizar el artículo sintetizando algunas de las conclusiones vertidas por los apartados tres, cuatro y cinco y señalando nuestras posturas con relación a cómo trabajar las relaciones transnacionales entre familias fronterizas.

En primer lugar, nos parece fundamental replantear el protagonismo de las mujeres como agentes de transnacionalización de las familias transfronterizas (su importancia al incentivar procesos de migración y economías compartidas entre peruanos y chilenos). Esto nos conduce a la necesidad de redimensionar la forma como se naturalizó, en los estudios transnacionales, a un "tipo ideal" de sujeto migrante: masculino e implicado en desplazamientos de larga distancia hacia localidades lejanas a las de vivienda en el país de origen. Paralelamente, la experiencia de las mujeres peruanas nos permite comprender que el transnacionalismo "desde abajo", a diferencia de lo que inicialmente propuso Portes (2003), no depende únicamente de la migración, sino que requiere (por lo menos en las zonas de frontera) de prácticas familiares translocales previas que construyan una memoria activa de conexión entre los territorios que están ahora separados por fronteras. Frecuentemente, las familias transfronterizas constituyen comunidades extensas que tuvieron sus prácticas translocales convertidas en transnacionales con el proceso de constitución de los Estados. Por esto, en zonas de frontera, es fundamental adoptar una mirada histórica sobre las familias, situando aquellos procesos que provocan su transnacionalización.Así, en estos espacios, una mirada sincrónica impediría al investigador observar adecuadamente la constitución histórica del proceso de nacionalización de las familias, lo que puede conducirlo a confundir la personificación de las agencias sociales e institucionales. En la frontera, para entender qué transnacionaliza a qué, es necesario mirar las relaciones familiares desde un punto de vista histórico y contextual. 
En segundo lugar, nos parece que, más allá de la dimensión espacial literal, habría que subrayar la reproducción social de las relaciones, afectos, economías y hogares en la definición de la transnacionalidad familiar, tal como lo proponía Gonzálvez (2007). Pese a que reconocemos y adherimos a la importancia de avanzar hacia la ruptura de nociones que contemplan un isomorfismo espacio-familia, asumimos que el criterio de definición basado centralmente en la separación literal entre los miembros es problemático. En síntesis: es antitética la propuesta de enfrentarnos al reduccionismo de las definiciones basadas en la cercanía literal y co-presencia de los miembros de las familias, adoptando una definición basada en la noción de radical distancia entre ellos. Básicamente porque las dos nociones están sentadas en un mismo principio conceptual: definen la familia a partir de una versión excesivamente materialista del espacio.

Si consideramos que el transnacionalismo migrante constituye un proceso de construcción de articulaciones entre localidades y entre países operado a través de las redes migrantes, entonces una familia debiera entenderse como transnacional siempre y cuando la articulación entre sus miembros provocara este proceso de conexión. Retomando a Besserer (2004), no se trata de medir las distancias literales que separan las gentes, sino pensar en el tipo e intensidad de los vínculos que las unen. Entonces, la noción social de la distancia puede ser construida por las dificultades y problemas relacionados al desplazamiento de las madres, por ejemplo, al otro lado de la frontera; o por los aprendizajes a partir de la experiencia de otros miembros de la familia que se fueron a países más lejanos.

En tercer lugar, también hay otros ejemplos de relación familiar en estas zonas de frontera en las que los miembros no viven "la mayor parte del tiempo separados". Pero, incluso teniendo más posibilidades de verse, siguen articulando sus afectos, sus capitales, sus emprendimientos económicos, sus lealtades y sus problemas entre dos países y a través de sus redes sociales (familiares y comunitarias). ¿Acaso estas familias no están operacionalizando una transnacionalización del territorio? ¿Dado que se ven más a menudo, no son acaso transnacionales? Si consideramos que lo transnacional en la familia no se mide en distancia, sino en la forma de articulación transfronteriza de los capitales, entonces estas dos indagaciones se contestan afirmativamente: las familias en la frontera son transnacionales. Pero no solamente transnacionales.

Finalmente, nos gustaría proponer que la categorización de las familias migrantes en zonas de frontera expande el concepto de interseccionalidad de factores de exclusión de género hacia ámbitos diferentes de aquellos propuestos por las teóricas feministas a partir de Crenshaw (1991, p. 1944). Para esta autora, la interseccionalidad de los factores de exclusión de las mujeres opera a partir del cruce de asignaciones y condiciones de clase, color de piel (lo que incluye las etiquetas raciales y étnicas), políticas, y culturales. Proponemos que esta interseccionalidad en los estudios de la condición femenina en las familias de frontera debe complementarse a partir de un segundo eje de cruces categóricos en las asignaciones que estas mujeres reciben (y que las posicionan en el campo social). En sus vidas cotidianas, estas mujeres son un cruce entre transnacionalismo, transfrontericidad, 
bi-nacionalidad y bi-residencialidad. Así, más que discutir infructuosamente por la aplicabilidad del concepto de familia transnacional o transfronteriza en territorios como Arica y Tacna, debemos indagar cómo es que el cruce entre estas condiciones gana vida en la experiencia cotidiana de las mujeres y de las familias; preguntándonos, a la vez, qué construcciones y procesos históricos han devenido en este estado de cosas. $\mathrm{O}$, en palabras de Márquez y Romo (2008, p. 2): "Si bien el uso alternado de los términos transfronterizos, transnacionales y binacionales puede parecer analíticamente confuso, los tres reflejan la realidad de las familias fronterizas".

\section{Referencias}

AGNEW, John. Borders on the mind: reframing border thinking. Ethics \& Global Politics, v. 1, n. 4, p. 175-191, 2008.

ÁLVAREZ JR, Robert. The Mexican-US border: the making of an anthropology of borderlands. Annual Review of Anthropology, n. 24, p. 447-470, 1995.

ALMIHAT, Anne-Laure. Are Borders More Easily Crossed Today? The Paradox of Contemporary Trans-Border Mobility in the Andes. Geopolitics, v. 2, n. 1, p. 1-18, 2007.

ARANDA, Elizabeth. Global Care Work and Gendered Constraints: The Case of Puerto Rican Transmigrants. Gender and Society, v. 17, n. 4, p. 609-626, 2003.

BAEZA, Pablo. De los enfoques "unidimensionales" a los enfoques "multidimensionales" en el estudio de las migraciones internacionales. Revista de Ciencias Sociales, n. 29, sem página, 2012.

BESSERER, Federico. Topografías Transnacionales: Hacia Una Geografia de la vida Transnacional. México-DF: Editorial Plaza y Valdés, 2004.

BOURDIEU, Pierre. Las Estrategias de la Reproducción Social. Buenos Aires: Siglo Veintiuno, 2011.

BRYCESON, Deborah;VUORELA, Ulla.Transnational Families in the 21st Century. In: BRYCESON, Deborah; VUORELA, Ulla (ed.). The Transnational Family: New European Frontiers and Global Networks. Oxford: Berg Publishers, 2002.

CARDIN, Eric. Trabalho e práticas de contrabando na fronteira do Brasil com o Paraguai. Revista Geopolíticas, v. 3, n. 2, p. 207-234, 2012.

CASTLES, Stephen. Globalización y migración: algunas contradicciones urgentes. Texto del discurso inaugural presentado en la Reunión del Consejo Intergubernamental del MOST, v. 16, n. 6, p. 82-97, 1997.

COE, Cati. What is the impact of transnational migration on family life? Women's comparisons of internal and international migration in a small town in Ghana. American Ethnologist, v. 38, n. 1, p. 148-163, 2011.

CRENSHAW, Kimberly. Mapping the margins: Intersectionality, identity politics, and violence against women of color. Stanford Law Review, n. 6, p. 1241-1299, 1991.

GLICK-SCHILLER, Nina, BASCH, Linda; BLANC-SZANTON, Cristine. Transnationalism: A new analytic framework for understanding migration. Annals of the New York Academy of Sciences, v. 645, n. 1, p. 1-24, 1992.

GONZÁlVEZ, Herminia. Familias y hogares transnacionales: una perspectiva de género. Puntos de Vista: Cuadernos del OMCI, n. 11, p. 7-25, 2007.

Los cuidados en el centro de la migración. La organización social de los cuidados transnacionales desde un enfoque de género. Revista Migraciones, n. 33, p. 127-153, 2013.

GONZÁlEZ, Sergio. La llave y el candado. El conflicto entre Perú y Chile por Tacna y Arica (1883-1929). Santiago: LOM, 2008. 
GONZÁLVEZ, Herminia; ACOSTA, Elaine. Cruzar las fronteras desde los cuidados: la migración transnacional más allá de las dicotomías analíticas. In: GUIZARDI, Menara (ed.). Las fronteras del Transnacionalismo. Límites y desbordes de la experiencia migrante en el centro y norte de Chile. Santiago: Ocho Libros, 2015.

GRIMSON, Alejandro. Disputas sobre las Fronteras. In: MICHAELSEN, Scott; JOHNSON, David (org.). Teoría de la frontera: los límites de la política cultural. Barcelona: Gedisa, 2003.

¿Fronteras políticas versus fronteras culturales? In: GRIMSON, Alejandro (org). Fronteras, Naciones e Identidades. Buenos Aires: CICCUS, 2000.

Fronteras, Estados e identificaciones en el cono sur. In: MATO, Daniel (ed.). Cultura, Política y Sociedad. Perspectivas Latinoamericanas. Buenos Aires: CLACSO, 2005.

HONDAGNEU-SOTELO, Pierrette. Feminism and Migration. Annals of the American Academy of Political and Social Science, n. 571, p.107-120, 2000.

KEARNEY, Michael. Borders and Boundaries of State and Self at the End of Empire. Journal of Historical Sociology, v. 4, n. 1, p. 52-74, 1991.

The Local and the Global: The Anthropology of Globalization and Transnationalism. Annual Review of Anthropology, n. 24, p. 547-565, 1995.

LEVITT, Peggy; GLICK-SCHILLER, Nina. Perspectivas internacionales sobre la migración: conceptualizar la simultaneidad. Migración y Desarrollo, n. 3, p. 60-91, 2004.

MÁRQUEZ, Raquel; ROMO, Harriett. Introduction. In: MÁRQUEZ, Raquel; ROMO, Harriet (ed.). Transformations of La Familia on the U.S.-Mexico Border. Indiana: University of Notre Dame Press, 2008.

MASSEY, Douglas et al. Theories of international migration: a review and appraisal. Population and Development, v. 19, n. 3, p. 431-466, 1993.

MCEVOY, Carmen. Guerreros y civilizadores. Política, sociedad y cultura en Chile durante la Guerra del Pacífico.Santiago: Ediciones UDP, 2011.

MOCTEZUMA, Miguel. Transnacionalidad y transnacionalismo. Papeles de Población, n. 57, p. 39-54, 2008.

PARELLA, Sonia. Los vínculos afectivos y de cuidado en las familias transnacionales. Migrantes ecuatorianos y peruanos en España. Migraciones Internacionales, v.4, n.2, p.151-188, 2007.

PARREÑAS, Rhacel. Long distance intimacy: class, gender and intergenerational relations between mothers and children in Filipino transnational families. Global Networks, v. 5, n. 4, p. 317-336, 2005.

PÉREZ, Carlos;VICUÑA, José Tomás; ROJAS, Tomás. Del contexto fronterizo y migratorio. In:VICUÑA, José Tomás; ROJAS, Tomás (ed.). Migración internacional en Arica y Parinacota: Panoramas y tendencias de una región fronteriza. Santiago: Ediciones Universidad Alberto Hurtado, 2015.

PERKMANN, Markus; SUM, Ngai-Ling. Globalization, regionalization and cross-border regions: scales, discourses and governance. London: Palgrave Macmillan, 2002.

PODESTÁ, Juan. Regiones fronterizas y flujos culturales: La peruanidad en una región chilena. Revista UNIVERSUM, v. 1, n. 26, p. 123-137, 2011.

PORTES, Alejandro. Theoretical Convergencies and Empirical Evidence in the Study of Immigrant Transnationalism. International Migration Review, v. 37, n. 3, p. 874-92, 2003.

Social Capital: Its origin and applications in Modern Sociology. In: LESSER, Eric (ed.). Knowledge and Social Capital: Foundations and Applications. Woburn, MA: Butterworth-Heinemann, 2000.

PORTES, Alejandro; GUARNIZO, Luis Eduardo; LANDOLT, Patricia. The study of transnationalism: pitfalls and promise of an emergent research field. Ethnic and racial studies, v. 22, n. 2, p. 217-237, 1999.

ROSENBLITT, Jaime. Centralidad geográfica, marginalidad política: La región Tacna-Arica y su comercio, 1778-1841. Santiago: Centro de Investigaciones Barros Arana, 2013. 
SATER, William. Andean tragedy: fighting the war of the Pacific, 1879-1884. Lincoln: University of Nebraska Press, 2007.

SØRENSEN, Nina. La familia transnacional de latinoamericanos/as en Europa. In: HERRERA, Gioconda; RAMÍREZ, Jacques (ed.). América Latina migrante: Estado, familias, identidades. Quito: FLACSO-Ecuador, 2008.

SØRENSEN, Nina;VAMMEN, Ida. Who cares? Transnational families in debates on migration and development. New Diversities, v. 16, n. 2, p. 89-108, 2014.

STEPHEN, Lynn. Conceptualizing Transborder Communities. In: ROSENBLUM, Mark;TICHENOR, Daniel (ed.). Oxford Handbook of the Politics of the International Migration. Oxford: Oxford University Press, 2012.

SUM, Ngai-Ling. Rethinking Globalisation: Re-articulating the Spatial Scale and Temporal Horizons of TransBorder Spaces. In: BRENNER, Neil; JESSOP, Bob; JONES, Martin; MACLEOD, Gordon (ed.). State/Space: A Reader. Oxford: Blackwell Publishing, 2003.

TAPIA, Marcela. Frontera y migración en el norte de a partir del análisis de los censos población: Siglos XIXXXI. Revista de geografía Norte Grande, n. 53, p. 177-198, 2012.

TAPIA, Marcela; PARELLA, Sonia. Las regiones fronterizas para el estudio de la migración y circulación. Un análisis a partir de dos casos ilustrativos. In GUIZARDI, Menara (Ed). Las fronteras del Transnacionalismo. Límites y desbordes de la experiencia migrante en el centro y norte de Chile. Santiago: Ocho Libros, 2015.

VICUÑA, José Tomás; PÉREZ, Carlos; ROJAS, Tomás. Características Económicas y socio-demográficas de la Región de Arica y Parinacota. In:VICUÑA, José Tomás; ROJAS, Tomás (ed.). Migración internacional en Arica y Parinacota: Panoramas y tendencias de una región fronteriza. Santiago: Ediciones Universidad Alberto Hurtado, 2015.

VITALE, Luis. Interpretación marxista de la historia de Chile. Santiago: LOM, 2011.

WILSON, Thomas; DONNAN, Hastings. Nation, State and Identity at International Border. In: (ed.).Border identities: nation and state at international frontiers. Cambridge: Cambridge University Press, 1998. 


\section{Reflections on Family Transnationalism in Border Territories}

Abstract

The articlediscusses the results of an ethnographic research developed between 2012 and 2015 on the Chilean-Peruvian border. In the study, we conducted 87 qualitative interviews, 250 ethnographic photographs, recorded all the experience in 47 weeks of fieldwork reports and applied a survey to 100 Peruvian migrant women. Analyzing these data, we reflect on the definitions of "transnational migrant families" seeking to understand if this category can be applied to border territories. We will start by synthesizing the discussions about transnationalism, transnational families and border territories. Then, we point out the dialectic constitution of national identity in the border area. We question the conceptual relationship between link and distance posed in the notion of transnationalized family and criticize the assumption of family transnationalism as a process of "development" of subjects and communities. In the final remarks, we synthesized our conceptual debate around three axes: rethinking the protagonism of women as agents of transnationalization of cross-border families; questioning the literal spatial dimension of families, and proposing that the categorization of migrant families in border areas expands the concept of factor intersectionality of gender exclusion.

Keywords: Transnational families, migration, border, gender.

\section{Resumo}

Discutimos os resultados de uma pesquisa etnográfica desenvolvidaentre 2012 e 2015 na fronteira Chile-Perú. Neste estudo, realizamos 87 entrevistas qualitativas, 250 fotografias etnográficas, registramos toda a experiência em 47 relatos semanais de trabalho de campo e aplicamos um questionário socioeconômico a 100 migrantes peruanas. Analisando estes dados, refletimos as definições de "famílias migrantes transnacionais", buscando entender se esta categoria se aplica a territórios fronteiriços. Partiremos sintetizando as discussões sobre transnacionalismo, famílias transnacionais e territórios de fronteira. Logo, abordamos a dialética constituição da identidade nacional na fronteira; questionamos a relação conceitual entre vínculo e distância exposta na noção de família transnacionalizada e criticamos a assunção do transnacionalismo familiar como um processo de "desenvolvimento" de sujeitos e comunidades. Nas considerações finais, sintetizamos nossas conclusões conceituais em torno de três eixos: repleteando o protagonismo das mulheres como agentes da transnacionalização das famílias transfronteiriças; questionando a dimensão espacial literal das famílias e propondo que a caracterização das famílias migrantes em zonas de fronteira expanda o conceito de intersecionalidade de fatores da exclusão de gênero.

Palavras-chave: Famílias Transnacionais, migração, fronteira, gênero.

Data de recebimento do artigo: 4/8/2017

Data de aprovação do artigo: 20/7/2018 